\title{
Vascular endothelial growth factor is increased during early stage of diabetic nephropathy in type II diabetic rats
}

\author{
Dae Ryong Cha ${ }^{1}$, Young Sun Kang ${ }^{1}$, Sang Youb Han ${ }^{2}$, Yi Hwa \\ Jee ${ }^{1}$, Kum Hyun Han ${ }^{1}$, Jee Young Han ${ }^{3}$, Young Sik Kim ${ }^{4}$ and \\ Nan Hee Kim ${ }^{1}$ \\ ${ }^{1}$ Department of Internal Medicine, College of Medicine, Korea University, Ansan, South Korea \\ ${ }^{2}$ Department of Internal Medicine, College of Medicine, Inje University, Ilsan, South Korea \\ ${ }^{3}$ Department of Anatomical Pathology, Inha University, Incheon, South Korea \\ ${ }^{4}$ Department of Anatomical Pathology, College of Medicine, Korea University, Ansan, South Korea \\ (Requests for offprints should be addressed to Nan Hee Kim, Department of Internal Medicine, Korea University Hospital, 516 Kojan-Dong, Ansan City, \\ Kyungki-Do, 425-020, South Korea; Email: nhkim@kumc.or.kr)
}

\begin{abstract}
Vascular endothelial growth factor (VEGF) has been implicated in the pathogenesis of diabetic nephropathy. We investigated serial changes of VEGF in the kidney and assessed whether glomerular and urinary VEGF levels are related to the severity of diabetic nephropathy. Furthermore, we examined the relationship between urinary VEGF levels and the urinary albumin excretion (UAE) rate in Otsuka-Long-Evans-Tokushima-Fatty (OLETF) rats. Glomerular VEGF mRNA expression and protein synthesis were evaluated by the reverse transcriptionpolymerase chain reaction, immunohistochemical staining and in situ hybridization. Urinary levels of VEGF were determined by enzyme-linked immunosorbent assay. UAE was significantly higher in OLETF rats than in control Long-Evans-Tokushima-Fatty (LETO) rats throughout the study period. Urinary VEGF levels were
\end{abstract}

significantly higher from 25 to 37 weeks, and then gradually reduced until 55 weeks, although the levels were still higher than those in control rats. Urinary VEGF levels also showed a significant positive correlation with UAE $(r=0.262, \quad P=0.045)$ and serum creatinine $(r=0.398$, $P=0.044)$, and were found to be independently correlated with UAE by Spearman's rank correlation. By immunohistochemical staining and in situ hybridization, VEGF was mainly detected in the podocytes in the glomeruli. Interestingly, a significant increase in VEGF mRNA expression was observed in the early period of diabetic nephropathy, and this was associated with increased urinary VEGF excretion. Thus, the overproduction of VEGF in the diabetic kidney may participate in the pathogenesis of early-stage diabetic nephropathy.

Journal of Endocrinology (2004) 183, 183-194

\section{Introduction}

Diabetic nephropathy is one of the most serious microvascular complications. The diabetic milieu results in the increased expression of angiogenic growth factors in numerous tissues in response to both hyperglycemia and tissue ischemia (Tilton et al. 1997, Duh \& Aiello 1999, Cruz et al. 2002). Moreover, vascular endothelial growth factor (VEGF) is known to be an endothelial mitogen and a potent vasopermeability factor (Ferrara 1999).

Recent evidence supports a direct role for VEGF in the pathogenesis of diabetic nephropathy. VEGF is upregulated early in diabetes mellitus, especially in podocytes (Cooper et al. 1999). In vivo, the blockade of VEGF by the administration of neutralizing antibodies to diabetic rats abolished hyperfiltration and suppressed the urinary albumin excretion (UAE) rate (De Vriese et al. 2001). In addition, VEGF may contribute to renal matrix accumulation, since treatment with anti-VEGF antibodies attenuates GBM thickening and mesangial expansion (Flyvbjerg et al. 2002). These findings indicate that an inappropriate rise in VEGF production in diabetes mellitus may increase glomerular vascular permeability and exacerbate proteinuria. Moreover, in support of the role of VEGF in proteinuria, serum concentrations of VEGF have been reported to be correlated with the risk and degree of albuminuria (Hovind et al. 2000, Santilli et al. 2001).

However, little in vivo evidence is available on the potential role of the VEGF system in type 2 diabetes mellitus. Although serum VEGF concentrations were found to be elevated in diabetic patients with albuminuria (Abdel Aziz et al. 1997, Wasada et al. 1998, Hovind et al. 2000), it is not known whether urinary VEGF excretion correlates with albuminuria. 
Otsuka-Long-Evans-Tokushima-Fatty (OLETF) rats are a genetic model of spontaneous non-insulin-dependent diabetes mellitus (NIDDM) development, and are considered a useful animal models in the study of the pathogenesis of diabetic nephropathy (Kawano et al. 1992, Fukuzawa et al. 1996). Due to their attractive characteristics, we performed this experiment using OLETF rats as a type II diabetic model.

In the present study, we investigated the relation of serial changes of VEGF in the kidney to the duration of diabetes mellitus in OLETF rats in order to clarify the implications of alterations in VEGF in the kidney with respect to diabetic nephropathy. We also investigated whether urinary VEGF levels are related to the severity of diabetic nephropathy, and the relationship between urinary VEGF levels and the UAE rate.

\section{Materials and Methods}

\section{Experimental animals}

Male OLETF rats, a model of type II diabetes mellitus, were kindly supplied by the Tokushima Research Institute (Otsuka Pharmaceutical, Tokushima, Japan). Male LongEvans-Tokushima-Fatty (LETO) rats served as a genetic control. All rats were kept at controlled temperature $\left(23 \pm 2{ }^{\circ} \mathrm{C}\right)$ and humidity $(55 \pm 5 \%)$ under artificial light cycle, and were given free access to rat chow. Fifteen LETO and 20 OLETF rats were included in the study. Animals were caged individually, and their weights and 24-h urine samples were collected by metabolic cage at certain time points $(17,25,37,45$ and 55 weeks). Blood samples were withdrawn when they were killed, and plasma glucose levels were measured by a glucose oxidasebased method; creatinine levels were determined by the modified Jaffe method. The study was performed in accordance with the institutional guidelines for animal research.

\section{Urinary albumin assays}

The amount of UAE was determined in 24-h urine samples from each animal. Albumin concentrations were determined by competitive enzyme-linked immunosorbent assay (ELISA). In brief, 96-well plates (Nunc, Naperville, IL, USA) were precoated with sheep antirat albumin $(250 \mathrm{ng} / \mathrm{ml})$, and incubated for $2 \mathrm{~h}$ with standard dilutions of rat albumin or diluted rat urine samples. After addition of standard dilutions or a sample in $200 \mu \mathrm{l}$ reaction buffer and equilibrating for $60 \mathrm{~min}$, horseradish peroxidase-labeled antirat albumin was added, and the reaction was then allowed to proceed for $30 \mathrm{~min}$ at room temperature (RT). Thereafter, the plates were rinsed again three times with PBST (PBS containing 0.05\% Tween-20), and substrate solution (prepared by dissolving
O-phenylenediamine in methanol at a concentration of $10 \mathrm{mg} / \mathrm{ml}$, diluting this $1: 100$ with deionized water, and adding $0.01 \mathrm{ml}$ of $30 \% \mathrm{H}_{2} \mathrm{O}_{2}$ per $100 \mathrm{ml}$ of the solution) was then added and incubation continued for $3 \mathrm{~h}$. After stopping the reaction with $4 \mathrm{M}$, the absorbance was read at $495 \mathrm{~nm}$ with an ELISA reader. The sheep antirat albumin antibodies and standards were purchased from Cappel Laboratories (West Chester, PA, USA). UAE values were normalized with respect to urine creatinine (urinary ACR).

\section{Histologic examination}

OLETF rats and age-matched LETO rats were anesthetized with pentobarbital sodium $(50 \mathrm{mg} / \mathrm{kg}$ i.p.). Kidneys were perfused with phosphate-buffered saline $(\mathrm{pH} 7 \cdot 4)$ through the aorta, rapidly fixed in 10\% phosphatebuffered formalin for $24 \mathrm{~h}$ and embedded in paraffin. One kidney was processed for immunohistochemical study and histologic examination. The other kidney was immediately placed in liquid nitrogen for subsequent RNA extraction. Paraffin slices from kidneys were stained with hematoxylin-eosin or periodic acid-Schiff (PAS). All histologic examinations were carried out by two pathologists in a blind manner.

Regarding glomerular histopathologic changes, mesangial lesions were scored semiquantitatively in terms of mesangial expansion and mesangial sclerosis. Mesangial expansion was graded into four scales $(0$, no sclerosis of the glomerulus; 1 , sclerosis of up to $25 \%$ of the glomerulus; 2 , sclerosis of $25-50 \%$ of the glomerulus; 3 , sclerosis of $50-75 \%$ of the glomerulus; 4 , sclerosis of more than $75 \%$ of the glomerulus. About 60 glomeruli were analyzed in the kidney sections of each rat, and these scores were compared for age-matched OLETF and LETO rats.

\section{Semiquantitative analysis of VEGF $m R N A$ expression}

Total RNA was extracted from renal cortical tissues with Trizol reagent, and cDNA was synthesized by reverse transcription with an RNA PCR kit (Applied Biosystems, Roche Inc., Foster City, CA, USA) in a $20 \mu \mathrm{l}$ mixture containing $1 \mu \mathrm{g}$ RNA, $50 \mathrm{mM} \mathrm{KCl}, 10 \mathrm{mM}$ Tris-HCl, $5 \mathrm{mM} \mathrm{MgCl}_{2}, 1 \mathrm{mM}$ of each dNTPs and oligo-(dT) primers, 20 units of RNase inhibitor, and 50 units of MuLV reverse transcriptase. The reaction mixture was incubated for $60 \mathrm{~min}$ at $42{ }^{\circ} \mathrm{C}$, and then at $90{ }^{\circ} \mathrm{C}$ for $7 \mathrm{~min}$ in a thermocycler (GeneAmp PCR system 9600, Perkin Elmer, Roche Molecular System, Branchburg, NJ, USA). Next, cDNA was amplified with 2.5 units of AmpliTaq Gold polymerase in a $25 \mu \mathrm{l}$ reaction volume containing $10 \mathrm{mmol} / 1 \quad$ Tris $-\mathrm{HCl} \quad(\mathrm{pH} \quad 8 \cdot 3), \quad 50 \mathrm{mmol} / 1 \quad \mathrm{KCl}$, $1.5 \mathrm{mmol} / 1 \mathrm{MgCl}_{2}, 0.2 \mathrm{mmol} / \mathrm{l}$ deoxynucleoside triphosphate, and $30 \mathrm{pmol}$ of each primer. Sequence-specific primers for VEGF, which included introns between amplification sites from exon 3 to the $3^{\prime}$ untranslated end, 
were used to amplify three splicing variants (VEGF120, VEGF164, and VEGF188). The expected lengths of their PCR products were; 330 base pairs (bp) for VEGF120, $462 \mathrm{bp}$ for VEGF164 and $514 \mathrm{bp}$ for VEGF188. The nucleotide sequences of each primer were as follows: sense 5'-GAC CCT GGT GGA CAT CTT CCA GGA-3' and antisense 5'-GGT GAG AGG TCT AGT TCC CGA-3'. $\beta$-Actin was also amplified as an internal control, and the expected length of its PCR product was $460 \mathrm{bp}$. The nucleotide sequences of the primers were as follows: sense 5'-TCA TGA GGT AGT CCG TCA GG-3' and antisense 5'- TCT AGG CAC CAA GGT GTG-3'. The PCR conditions consisted of an initial denaturation at $94{ }^{\circ} \mathrm{C}$ for $7 \mathrm{~min}$, followed by 35 cycles (VEGF) or 38 cycles ( $\beta$-actin) of denaturation at $94^{\circ} \mathrm{C}$ for $45 \mathrm{~s}$, annealing at $58{ }^{\circ} \mathrm{C}(\mathrm{VEGF})$, or $60{ }^{\circ} \mathrm{C}(\beta$-actin) for $45 \mathrm{~s}$, and extension at $72{ }^{\circ} \mathrm{C}$ for $3 \mathrm{~min}$, and these cycles were followed by a final extension at $72{ }^{\circ} \mathrm{C}$ for $7 \mathrm{~min}$. The number of PCR cycles was selected to represent a point before the product amplification plateau, as described previously (Cha et al. 2000). To confirm the identity of each PCR product, each of the electrophoresed PCR bands was extracted with a DNA extraction kit (Qiagen, Valencia, CA, USA) and sequenced by an ABI automated DNA sequencing system (ABI Genetic Analyzer 310; PRISM, Branchburg Park, NJ, USA). The RT-PCR products were separated on a $2 \%$ agarose gel by electrophoresis and ethidium bromide stained. After scanning at 300 d.p.i., blots were quantified by densitometric analysis with NIH image-analysis software (Version 1.61). VEGF mRNA expression was quantified after correcting for $\beta$-actin. Results were expressed as a mean optical density ratio of VEGF188/ $\beta$-actin, VEGF164/ $\beta$-actin and VEGF120/ $\beta$-actin.

\section{Immunohistochemical staining for VEGF}

For immunohistochemical staining, renal tissue was immediately fixed in 10\% neutral buffered formalin, cast in paraffin, sliced into 3- $\mu \mathrm{m}$-thick sections, and placed on microscope slides. After removal and dehydration in xylene and graded alcohols, slides were immersed in distilled water. Kidney sections were transferred to a $10 \mathrm{mmol} / \mathrm{l}$ citrate buffer solution for antigen retrieval at $\mathrm{pH} 6.0$ and then microwaved for $10 \mathrm{~min}$. After a water wash, $0 \cdot 05 \%$ peroxide/methanol was applied for $15 \mathrm{~min}$ to block endogenous peroxidase. The primary antibody, polyclonal rabbit antirat VEGF (Biogenex, San Ramon, CA, USA) antibody, was added at a 1:20 dilution for $2 \mathrm{~h}$ at RT. Negative control sections were stained under identical conditions by omitting the primary antibody. Using an LASB kit/HRP (DAKO, Carpinteria, CA, USA), kidney sections were sequentially treated with normal goat serum, primary antibody, link antibody, streptavidin-biotin horseradish peroxidase, and aminoethylcarbamisole (chromogen). Sections were then counterstained with Mayer's hematoxylin.
To evaluate VEGF staining, each glomerulus was graded semiquantitatively. Each score reflects changes in the extent rather than in the intensity of staining. Five scores were awarded, as follows; 0 , very weak or absent staining and no localized increases in staining; 1, diffuse, weak staining with $1-25 \%$ of the glomerulus showing focally increased staining; 2, 25-50\% of the glomerulus demonstrating a focal, strong staining; $3,50-75 \%$ of the glomerulus stained strongly in a focal manner; 4, more than $75 \%$ of the glomerulus stained strongly. For each sample, 50-60 glomeruli were evaluated, and the average score was calculated. Each slide was scored by an observer unaware of the experimental details.

\section{In situ hybridization}

Oligodeoxynucleotide sequences were designed based on the rat VEGF sequence corresponding to the basenumbered 522-551 coding region. Oligodeoxynucleotides were synthesized and supplied by Biognostik (Göttingen, Germany), and these probes were labeled with fluorescein by a standard end labeling reaction. Fluorescein-labeled in situ hybridization was performed with an InnoGenex ISH kit (InnoGenex, San Ramon, CA, USA), according to the manufacturer's instructions. In brief, sections of $4 \mu \mathrm{m}$ were cut from $10 \%$ formalin-fixed, paraffinembedded tissues. Sections were dewaxed, treated with proteinase $\mathrm{K}(10 \mu \mathrm{g} / \mathrm{ml})$ at $\mathrm{RT}$ for $10 \mathrm{~min}$ and washed three times in 1 PBS for $2 \mathrm{~min}$. They were then treated with Target Retrieval Solution containing a 0.2\% RNase block, placed in a microwave for $15 \mathrm{~min}$, and then cooled for $20 \mathrm{~min}$. Sections were then washed three times in solutions containing $0 \cdot 2 \%$ RNase block for 5 min, briefly refixed in $1 \%$ formaldehyde for $10 \mathrm{~min}$, and rinsed in deionized water for $5 \mathrm{~min}$. Sense and antisense probes were diluted to $100 \mathrm{ng} / \mathrm{ml}$ in hybridization buffer containing $50 \%$ formamide, and heated to $80{ }^{\circ} \mathrm{C}$ for $5 \mathrm{~min}$. A volume of $10-50 \mu \mathrm{l}$ of this solution was then applied to the slides under cover slips. Hybridization was performed at $37^{\circ} \mathrm{C}$ for $3 \mathrm{~h}$. After hybridization, sections were washed in 2 PBS containing $0 \cdot 1 \%$ Tween-20 for $10 \mathrm{~min}$. After three 5-min washes in 1 PBS containing $0 \cdot 1 \%$ Tween-20, blocking buffer was applied to the sections for $5 \mathrm{~min}$ at $\mathrm{RT}$, and then they were incubated in PBS solutions containing antifluorescein antibody and $15 \mathrm{mM}$ sodium azide for 20 min at RT. After 5-min wash 1 PBS containing $0 \cdot 1 \%$ Tween-20 for $5 \mathrm{~min}$, and streptavidin-alkaline phosphatase conjugate in PBS containing stabilizer and $15 \mathrm{mM}$ sodium azide were incubated on slides at RT for $20 \mathrm{~min}$. After three 5-min washes in PBS, activation buffer containing alkaline phosphatase activator in Tris$\mathrm{HCl}(\mathrm{pH} 9 \cdot 5)$ and $15 \mathrm{mM}$ sodium azide was applied for $1 \mathrm{~min}$, and the sections were then washed three times in 1 PBS for $5 \mathrm{~min}$, coated with developing solution containing NBT/BCIP, incubated in the dark for 6-12 h, and washed three times with PBS. They were then counterstained 
Table 1 Clinical characteristics of LETO and OLETF rats

\begin{tabular}{|c|c|c|c|c|c|}
\hline & $n$ & $\begin{array}{l}\text { Body weight } \\
\text { (g) }\end{array}$ & $\begin{array}{l}\text { Plasma glucose } \\
(\mathrm{mmol} / \mathrm{l})\end{array}$ & $\begin{array}{l}\text { Creatinine } \\
(\mu \mathrm{mol} / \mathrm{l})\end{array}$ & $\begin{array}{l}\text { Urinary albumin } \\
(\mathrm{mg} / \mathrm{mgCr})\end{array}$ \\
\hline \multicolumn{6}{|l|}{ Group } \\
\hline \multicolumn{6}{|l|}{17 weeks } \\
\hline LETO & 3 & $440 \pm 29$ & $4 \cdot 72 \pm 0.99$ & $53 \cdot 0 \pm 5 \cdot 3$ & $0 \cdot 35 \pm 0 \cdot 04$ \\
\hline OLETF & 4 & $510 \pm 14^{*}$ & $6 \cdot 66 \pm 1 \cdot 22$ & $54 \cdot 8 \pm 8 \cdot 8$ & $1 \cdot 80 \pm 0.08^{*}$ \\
\hline \multicolumn{6}{|l|}{25 weeks } \\
\hline LETO & 3 & $510 \pm 56$ & $6.94 \pm 0.94$ & $53 \cdot 0 \pm 7 \cdot 1$ & $0 \cdot 20 \pm 0 \cdot 03$ \\
\hline OLETF & 4 & $585 \pm 21^{*}$ & $10 \cdot 55 \pm 0.89$ & $55 \cdot 7 \pm 9 \cdot 7$ & $9 \cdot 12 \pm 2 \cdot 04^{* *}$ \\
\hline \multicolumn{6}{|l|}{37 weeks } \\
\hline LETO & 3 & $527 \pm 58$ & $6 \cdot 94 \pm 1 \cdot 11$ & $53 \cdot 3 \pm 12 \cdot 4$ & $0 \cdot 30 \pm 0 \cdot 04$ \\
\hline OLETF & 4 & $610 \pm 27^{*}$ & $13 \cdot 88 \pm 0 \cdot 94^{*}$ & $44 \cdot 2 \pm 7 \cdot 9$ & $44 \cdot 20 \pm 6 \cdot 11^{\dagger}$ \\
\hline \multicolumn{6}{|l|}{45 weeks } \\
\hline LETO & 3 & $480 \pm 14$ & $6 \cdot 98 \pm 1 \cdot 83$ & $38 \cdot 9 \pm 15 \cdot 0$ & $0.55 \pm 0.13$ \\
\hline OLETF & 4 & $630 \pm 14^{*}$ & $13 \cdot 60 \pm 1 \cdot 49^{*}$ & $39 \cdot 9 \pm 10 \cdot 6$ & $54 \cdot 80 \pm 6 \cdot 16^{\dagger}$ \\
\hline \multicolumn{6}{|l|}{55 weeks } \\
\hline LETO & 3 & $516 \pm 18$ & $6 \cdot 96 \pm 1 \cdot 15$ & $51 \cdot 3 \pm 9 \cdot 7$ & $0 \cdot 50 \pm 0 \cdot 11$ \\
\hline OLETF & 4 & $655 \pm 13^{*}$ & $14 \cdot 78 \pm 1 \cdot 61^{*}$ & $45 \cdot 9 \pm 13 \cdot 3$ & $86 \cdot 20 \pm 9 \cdot 19^{\dagger}$ \\
\hline
\end{tabular}

Values are expressed as mean \pm S.D. Comparisons were made between age-matched LETO and OLETF rats. ${ }^{*} P<0 \cdot 05$ vs LETO; ${ }^{* *} P<0 \cdot 01$ vs LETO; ${ }^{+} P<0 \cdot 001$ vs LETO.

with Nuclear Fast Red, and mounted with permanent mounting medium. As a negative control, in situ hybridization using sense probes was also performed.

\section{Measurement of VEGF concentrations in urine}

The amount of VEGF protein in 24-h urine was determined by a commercially available quantitative sandwich enzyme immunoassay ( $R \& D$ Systems, Minneapolis, MN, USA), according to the manufacturer's instructions. Urine samples were collected at $24-\mathrm{h}$ intervals. All particulates were removed by centrifugation at $4000 \mathrm{~g}$ for $10 \mathrm{~min}$, and samples were stored at $-70{ }^{\circ} \mathrm{C}$ before VEGF protein quantitation. The VEGF assay used is specific for the most common VEGF isoform, VEGF-165, but no data were available from the manufacturer concerning its specificity for the other isoforms. Before the study, the assay was validated for urine samples. Appropriate reductions in determined VEGF levels were observed by serially diluting urine samples. The assay was performed in duplicate, and results are expressed as means. Urinary VEGF levels were measured as described previously (Cha et al. 2000). We also examined the stability of VEGF in urine, particularly in acidic versus nonacidic urine, but no difference was found. The detection limit of the assay was $5 \mathrm{pg} / \mathrm{ml}$, and its coefficients of variation for intra-assay and interassay precision were $8.3 \%$ and $10.5 \%$ respectively. This ELISA showed no cross-reactivity with other cytokines or growth factors. To control for urine concentration differences, urinary VEGF was expressed relative to urinary creatinine content, and expressed as VEGF (pg/mg Cr).

\section{Statistical analysis}

We used nonparametric analysis because most of the variables, especially urinary VEGF, were not normally distributed even after logarithmic transformation. The Mann-Whitney $U$ test was used to compare two groups, and correlations between urinary VEGF and clinical parameters were examined by Spearman's rank correlation and multiple stepwise regression analysis. A significance level of $5 \%$ was chosen for all tests $(P=0 \cdot 05)$. All statistical analyses were performed with SPSS for Windows $10 \cdot 0$ (SPSS Inc., Chicago, IL, USA).

\section{Results}

\section{Clinical characteristics of OLETF rats}

The body weights of age-matched OLETF rats were significantly higher than those of LETO rats throughout the study period. Plasma glucose levels were higher in OLETF rats during study periods, and there was a statistically significant difference after 37 weeks of age in the age-matched OLETF rats. No significant difference was observed in the serum creatinine concentrations of the two groups. UAE albumin creatinine ratio (ACR) in the OLETF rats was significantly higher than in the LETO rats even at 17 weeks $(1.80 \pm 0.08 \mathrm{mg} / \mathrm{mg} \mathrm{Cr}$ in OLETF and $0.35 \pm 0.04 \mathrm{mg} / \mathrm{mg} \mathrm{Cr}$ in LETO; $P<0 \cdot 05)$ (Table 1). The amount of $24-\mathrm{h}$ UAE at the time of the final observation (55 weeks of age) was $86 \cdot 20 \pm$ $9.19 \mathrm{mg} / \mathrm{mg} \mathrm{Cr}$ in OLETF rats and $0.50 \pm 0.11 \mathrm{mg} / \mathrm{mg}$ $\mathrm{Cr}$ in LETO rats $(P<0 \cdot 001)$. Thus, UAE increased as did the difference between the UAE rates of OLETF and LETO rats with the duration of diabetes mellitus (Table 1).

\section{Histopathologic changes in OLETF rats}

Figure 1 shows the glomerular pathologies of OLETF and LETO rats at each time point. No significant changes in 

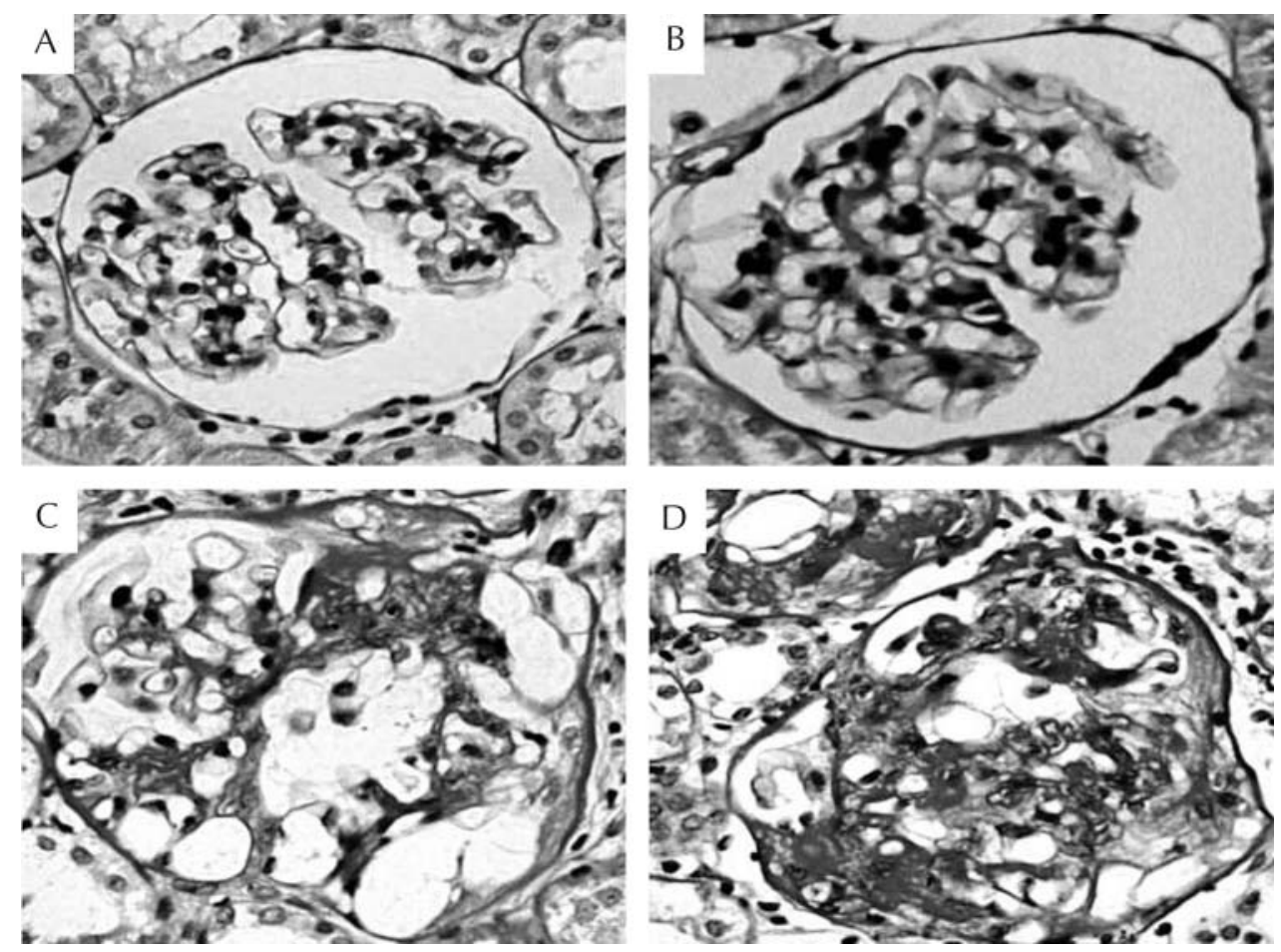

Figure 1 Light micrographs of glomeruli from experimental animals versus duration of diabetes mellitus. (A) LETO rat at 55 weeks of age; (B) OLETF rat at 17 weeks; (C) OLETF rat at 37 weeks; (D) OLETF rat at 55 weeks. Mesangial matrix and mesangial sclerosis increased in OLETF rats with diabetes mellitus duration. $\times 400$; PAS stain.

glomerular morphology were observed in LETO rats during the study period. Early changes of glomeruli in OLETF rats were focal and segmental, and mesangial cell proliferation was not observed during the study period. Mesangial expansion was initially observed in OLETF rats from 17 weeks of age, and this progressed with diabetes mellitus duration. Mesangial expansion was significantly higher in OLETF rats than in LETO rats throughout the observation period (Table 2). Mesangial sclerotic lesions were detected at 25 weeks of age in OLETF rats; thereafter, the sclerotic lesion scores of OLETF and LETO rats were significantly different. Significantly greater increases in mesangial sclerosis scores were observed in
OLETF rats than in LETO rats at 25 weeks (OLETF $0 \cdot 16 \pm 0.05$ vs LETO $0.01 \pm 0 ; \quad P<0 \cdot 05), 37$ weeks (OLETF $0 \cdot 36 \pm 0 \cdot 11$ vs LETO $0 \cdot 02 \pm 0 \cdot 01 ; P<0 \cdot 05), 45$ weeks (OLETF $0.44 \pm 0.12$ vs LETO $0.02 \pm 0 \cdot 01$; $P<0 \cdot 001$ ), and 55 weeks (OLETF $0 \cdot 78 \pm 0 \cdot 21$ vs LETO $0 \cdot 03 \pm 0 \cdot 02 ; P<0 \cdot 001)$ (Table 2$)$.

\section{Urinary excretion of VEGF protein}

Urinary VEGF concentrations were higher in OLETF rats at 17 weeks of age, and significantly higher levels were observed at 25-37 weeks of age. This difference then gradually reduced over the course of the observation

Table 2 Renal pathologic scores for mesangial expansion and mesangial sclerosis

\begin{tabular}{|c|c|c|c|c|}
\hline 17 weeks & 25 weeks & 37 weeks & 45 weeks & 55 weeks \\
\hline $0 \cdot 01 \pm 0$ & $0 \cdot 01 \pm 0$ & $0.02 \pm 0.01$ & $0.03 \pm 0.01$ & $0.03 \pm 0.02$ \\
\hline $0 \cdot 10 \pm 0.01^{*}$ & $1 \cdot 50 \pm 0.02^{*}$ & $1 \cdot 67 \pm 0.03^{*}$ & $2 \cdot 70 \pm 0.05^{\dagger}$ & $2 \cdot 90 \pm 0 \cdot 19^{\dagger}$ \\
\hline $0 \pm 0$ & $0 \cdot 01 \pm 0$ & $0 \cdot 02 \pm 0 \cdot 01$ & $0.02 \pm 0.01$ & $\begin{array}{l}0.03 \pm 0.02 \\
0.78+0.21^{\dagger}\end{array}$ \\
\hline $0.06 \pm 0.02$ & $0 \cdot 16 \pm 0.05^{*}$ & $0 \cdot 36 \pm 0 \cdot 11^{*}$ & $0 \cdot 44 \pm 0 \cdot 12^{\dagger}$ & $0 \cdot 78 \pm 0.21^{\dagger}$ \\
\hline
\end{tabular}

Values are expressed as mean \pm S.D. Comparisons were made between age-matched LETO and OLETF rats. ${ }^{*} P<0 \cdot 05$ vs LETO; ${ }^{\dagger} P<0 \cdot 001$ vs LETO. 
A

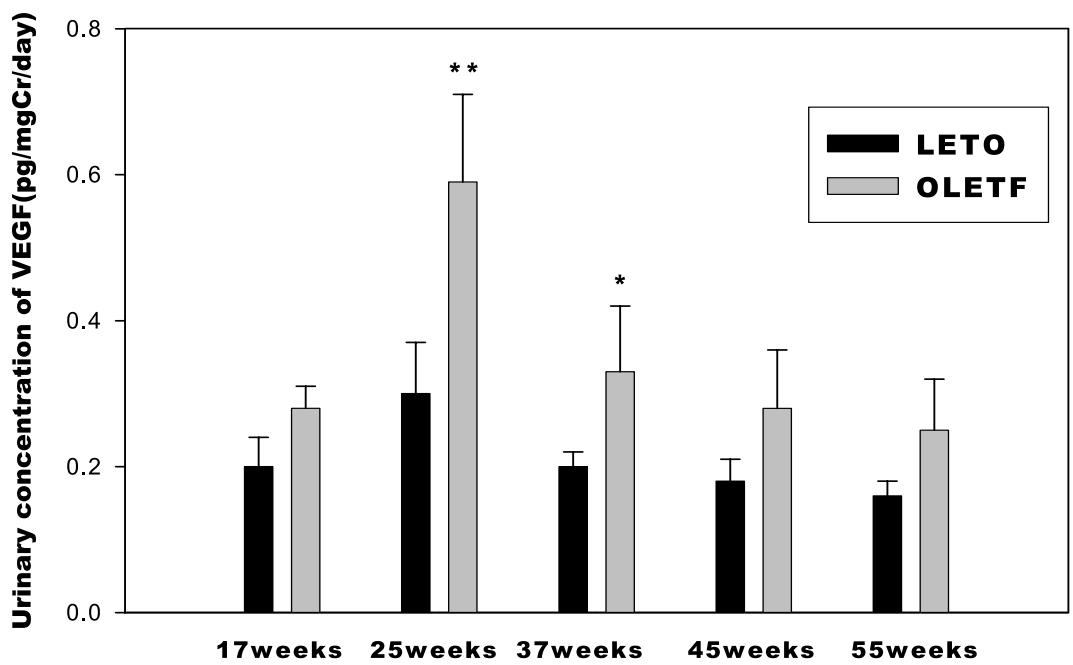

B

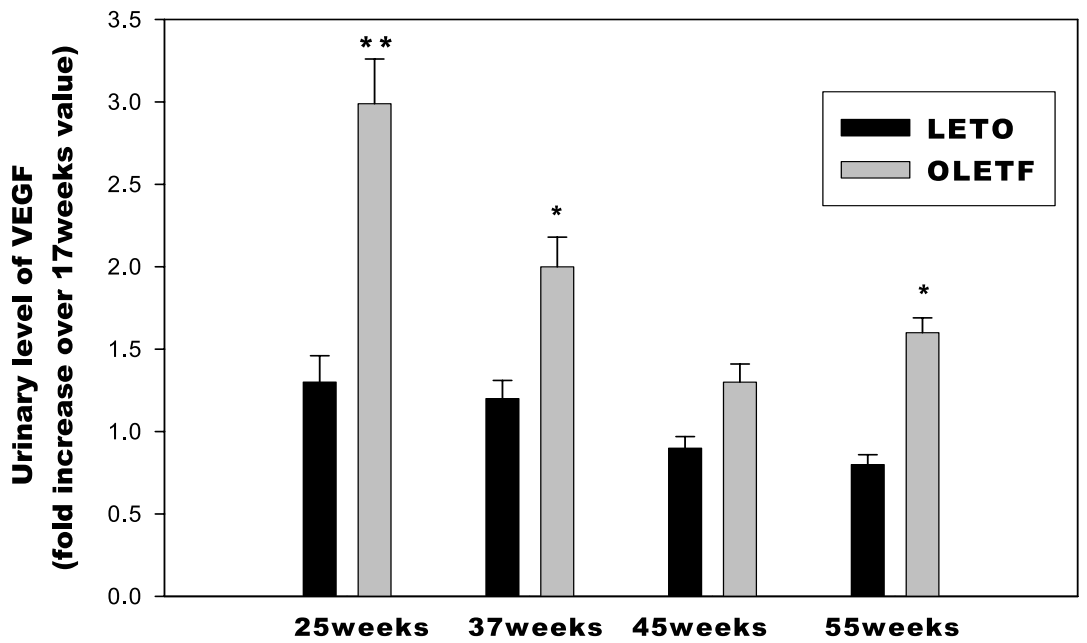

Figure 2 Urinary excretion of VEGF in experimental animals versus diabetes mellitus duration. VEGF proteins were measured in 24-h urine samples by enzyme-linked immunosorbent assay (ELISA). (A) Urinary VEGF concentrations were normalized versus urine creatinine concentration. Urinary VEGF levels were significantly higher at 25 and 37 weeks of age in OLETF rats than in age-matched LETO controls. (B) Fold increase of urinary excretion with respect to the value at 17 weeks in the same animals versus diabetes mellitus duration. Urinary VEGF excretion was maximally differentially increased at 25 weeks of age in OLETF rats versus 17 weeks of age. Data are shown as means \pm S.D. * $P<0 \cdot 05,{ }^{*} P<0 \cdot 001$ vs LETO.

period, but remained higher at 55 weeks of age. Interestingly, an abrupt increase in urinary VEGF excretion was found in OLETF rats at 25 weeks of age, after which it decreased gradually until study completion (Fig. 2A). The urinary levels of VEGF at 25 weeks of age were $0.59 \pm 0.12 \mathrm{pg} / \mathrm{mg} \mathrm{Cr}$ per day in OLETF rats and $0 \cdot 30 \pm 0.07 \mathrm{pg} / \mathrm{mg}$ Cr per day in LETO rats $(P<0 \cdot 001)$. The amounts of urinary VEGF at study completion were
$0.25 \pm 0.07 \mathrm{pg} / \mathrm{mg} \mathrm{Cr}$ per day in OLETF rats and $0 \cdot 16 \pm 0.02 \mathrm{pg} / \mathrm{mg}$ Cr per day in LETO rats $(P>0 \cdot 05)$; that is, they remained higher in OLETF rats.

Figure $2 \mathrm{~B}$ shows the fold increase of urinary VEGF excretion over the baseline value at 17 weeks in urinary VEGF level versus the duration of diabetes mellitus in OLETF rats. No significant change in the urinary excretion of VEGF was observed in LETO rats. However, 
urinary excretion of VEGF in OLETF rats was significantly elevated to $2 \cdot 99$-fold higher at 25 weeks $(P<0 \cdot 001)$, 2 -fold higher at 37 weeks $(P<0 \cdot 05), 1 \cdot 3$-fold higher at 45 weeks $(P>0 \cdot 05)$ and $1 \cdot 6$-fold higher at 55 weeks $(P<0 \cdot 05)$. Urinary VEGF excretion peaked at 25 weeks in OLETF rats.

Regarding the relationship between clinical parameters and urinary VEGF levels, urinary VEGF levels appeared to be positively correlated with urinary ACR $(r=0.262$, $P=0.045)$ and serum creatinine $(r=0.398, P=0.044)$. However, no correlations were found between urinary VEGF and other clinical parameters such as plasma glucose level or body weight. Multiple regression analysis showed urinary ACR as a dependent variable, and urinary VEGF was included in the model $\left(\mathrm{R}^{2}=63.5 \%, P<0 \cdot 01\right)$.

\section{Expression of VEGF $m R N A$ and protein in the glomerulus}

RT-PCR from cortical renal tissues demonstrated three alternative splicing variants: 330, 462 and 514 bp DNA fragments, corresponding to VEGF120, VEGF164 and VEGF188 (Fig. 3). The expression pattern of each isoform was similar in each experimental animal. In the present study, VEGF120 isoform expression was greater than those of VEGF164 and VEGF188 in renal cortical tissues. Glomerular mRNA expression of VEGF was higher in OLETF rats than in LETO rats throughout the study period. At 17 weeks of age, glomerular VEGF164 and VEGF188 isoform mRNA expression was slightly higher in OLETF rats, and VEGF120 isoform expression was significantly higher in OLETF rats than in LETO rats. However, VEGF mRNA expression increased abruptly at 25 weeks of age in OLETF rats, and at 37 weeks of age showed a maximal difference versus LETO rats (Fig. 3). After 45 weeks of age, glomerular VEGF mRNA expression reduced gradually, but remained higher in OLETF rats than in LETO rats. The VEGF: $\beta$-actin ratios in OLETF rats at $17,25,37,45$, and 55 weeks were $1 \cdot 28$-, $1 \cdot 59$-, 1.58-, 1.27- and 1.13-fold higher than those in LETO rats. It is of interest that a significant increase in VEGF mRNA expression was observed in the early period of diabetic nephropathy (25 and 37 weeks), and that this did not increase according to diabetic nephropathy stage. Interestingly, increases in the glomerular mRNA expression of VEGF were associated with an abrupt increase in the urinary VEGF excretion.

Figure 4 shows the representative glomerular immunohistochemical staining pattern of VEGF. Immunohistochemical staining and in situ hybridization for VEGF demonstrated that VEGF was mainly stained in the glomerular visceral epithelial cells in both OLETF and LETO rats (Fig. 5). By semiquantitative scoring, significantly elevated VEGF staining was observed in the glomeruli of OLETF rats at 25 weeks of age $(1 \cdot 75 \pm 0 \cdot 15$ in OLETF rats and $0.67 \pm 0.09$ in LETO rats; $P<0.01)$. VEGF immunostaining scores were higher in OLETF rats at 17 weeks (OLETF 0.82 \pm 0.09 vs LETO 0.62 \pm 0.07 ; $P>0 \cdot 05), 25$ weeks (OLETF $1 \cdot 75 \pm 0 \cdot 15$ vs LETO $0 \cdot 67 \pm$ $0 \cdot 09 ; P<0 \cdot 01), 37$ weeks (OLETF $1.50 \pm 0 \cdot 91$ vs LETO $0 \cdot 91 \pm 0 \cdot 11 ; P<0 \cdot 05), 45$ weeks (OLETF $1 \cdot 80 \pm 0 \cdot 16$ vs LETO $0.90 \pm 0.13 ; P<0.05$ ) and 55 weeks (OLETF $2 \cdot 30 \pm 0 \cdot 12$ vs LETO $1 \cdot 00 \pm 0 \cdot 15 ; P<0 \cdot 01$ ) (Fig. 6)

Figure 7 summarizes serial changes in UAE, urinary VEGF excretion, and glomerular VEGF mRNA transcription and protein levels in OLETF rats; UAE was progressively increased until 55 weeks of age. Glomerular VEGF mRNA and urinary VEGF excretion increased in concert to a peak level at 25 weeks of age, and then gradually decreased. However, glomerular VEGF protein levels showed a sudden increase at 25 weeks of age, and thereafter progressively increased with the duration of diabetes mellitus. It is of interest that glomerular VEGF gene transcription and the urinary excretion of VEGF were maximally elevated during the early stage of diabetic nephropathy.

\section{Discussion}

In the present study, we found that VEGF mRNA expression increases significantly during the early period of diabetic nephropathy, and that glomerular VEGF gene transcription is associated with elevation in the urinary VEGF level. Interestingly, urinary VEGF levels demonstrated a significant positive correlation with UAE and serum creatinine, and were found to be independently correlated with UAE.

These findings agree with those of a previous report that found that renal VEGF mRNA expression increases during the early period of diabetic nephropathy in type II diabetic rats (Tsuchida et al. 1999, Braun et al. 2001, Hoshi et al. 2002). An early and persistent increase in renal VEGF gene expression was also described in streptozotocininduced diabetic rats (Cooper et al. 1999). However, previous studies have focused mainly on the expression of VEGF, and the excretion of urinary VEGF was not examined, nor was the relationship between these and UAE.

Recently, we demonstrated that urinary VEGF excretion is significantly increased according to the degree of proteinuria in patients with diabetes mellitus, and that pronounced VEGF upregulation occurs in glomerular podocytes in the early phase of diabetic nephropathy (Cha et al. 2000).

VEGF is strongly implicated in the pathogenesis of diabetic microvascular complications, because it increases vascular permeability to macromolecules and stimulates monocyte chemotaxis and tissue factor production, all of which can contribute to microvascular complications (Clauss et al. 1990, Dvorak et al. 1995). Although the role of VEGF in regulating glomerular permeability has not yet been defined, a growing body of clinical and experimental evidence indicates that VEGF may be involved in altered 
A

$$
\text { MM L(17) O(17) L(25) O(25) L(37) O(37) L(45) O(45) L(55) O(55) } \rightarrow \begin{aligned}
& \text { Experimental } \\
& \text { Animal(weeks) }
\end{aligned}
$$

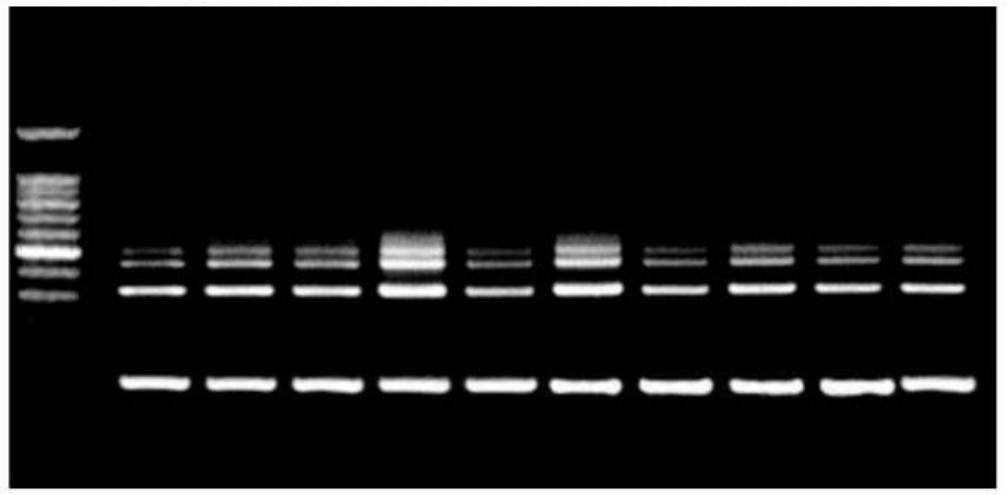

B

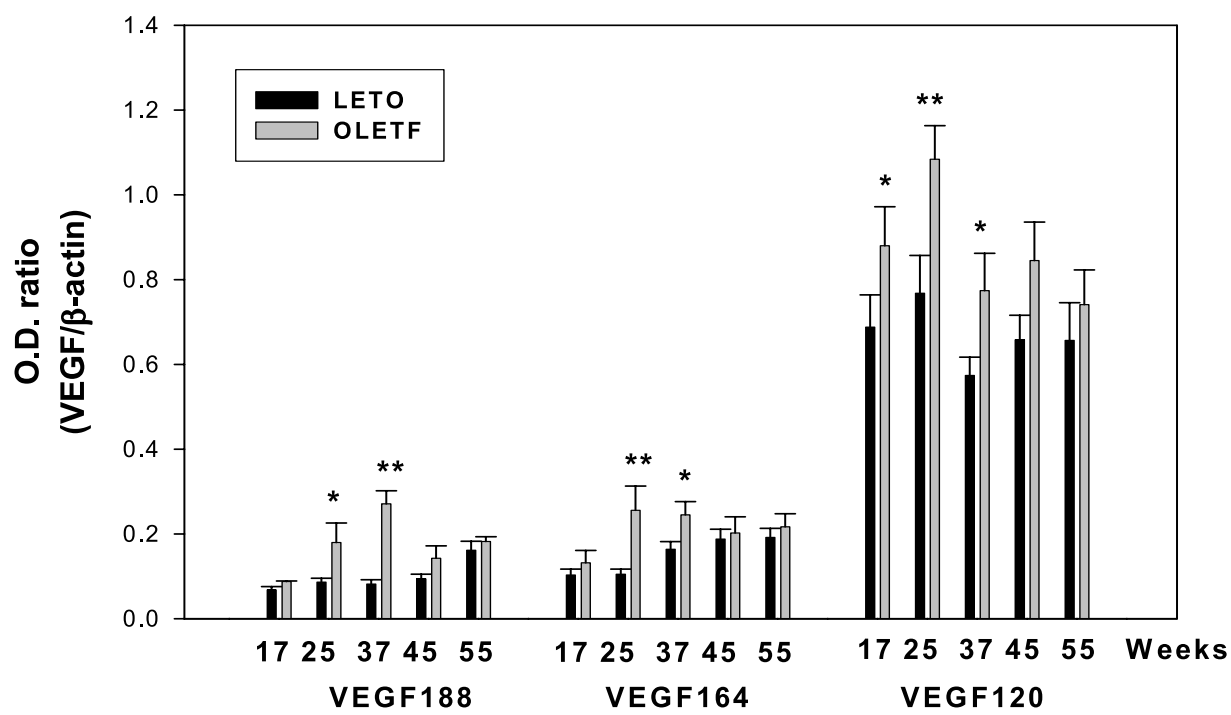

Figure 3 Renal VEGF mRNA expression in experimental animals versus diabetes mellitus duration. (A) Representative reverse transcription-polymerase chain reaction showing the $330 \mathrm{bp}$ product, which is identical to that of the alternatively spliced VEGF120 isoform. A second $462 \mathrm{bp}$ product, corresponding to the VEGF164 isoform, and a third 514 bp product, corresponding to the VEGF188 isoform, were also detected. (B) Densitometric analysis of RT-PCR data: results are expressed as an optical density ratio of VEGF188/ $\beta$-actin, VEGF164/ $\beta$-actin and VEGF120/ $\beta$-actin. VEGF120 isoform expression was greater than those of VEGF164 and VEGF188 in renal cortical tissues. Data shown are means \pm S.D. The VEGF gene transcript was significantly elevated at 25 and 37 weeks of age in OLETF rats versus age-matched LETO rats. * $P<0 \cdot 05$, ** $P<0.001$ vs LETO.

glomerular permeability (Shulman et al. 1996, Horita et al. 1998, Matsumoto \& Kanmatsuse 2001). However, it remains controversial as to whether VEGF has a causative role in the pathogenesis of albuminuria. Disagreements between studies (Klanke et al. 1998, Webb et al. 1999) on this point may be ascribed to the use of different experimental animals or different models of glomerular diseases. 

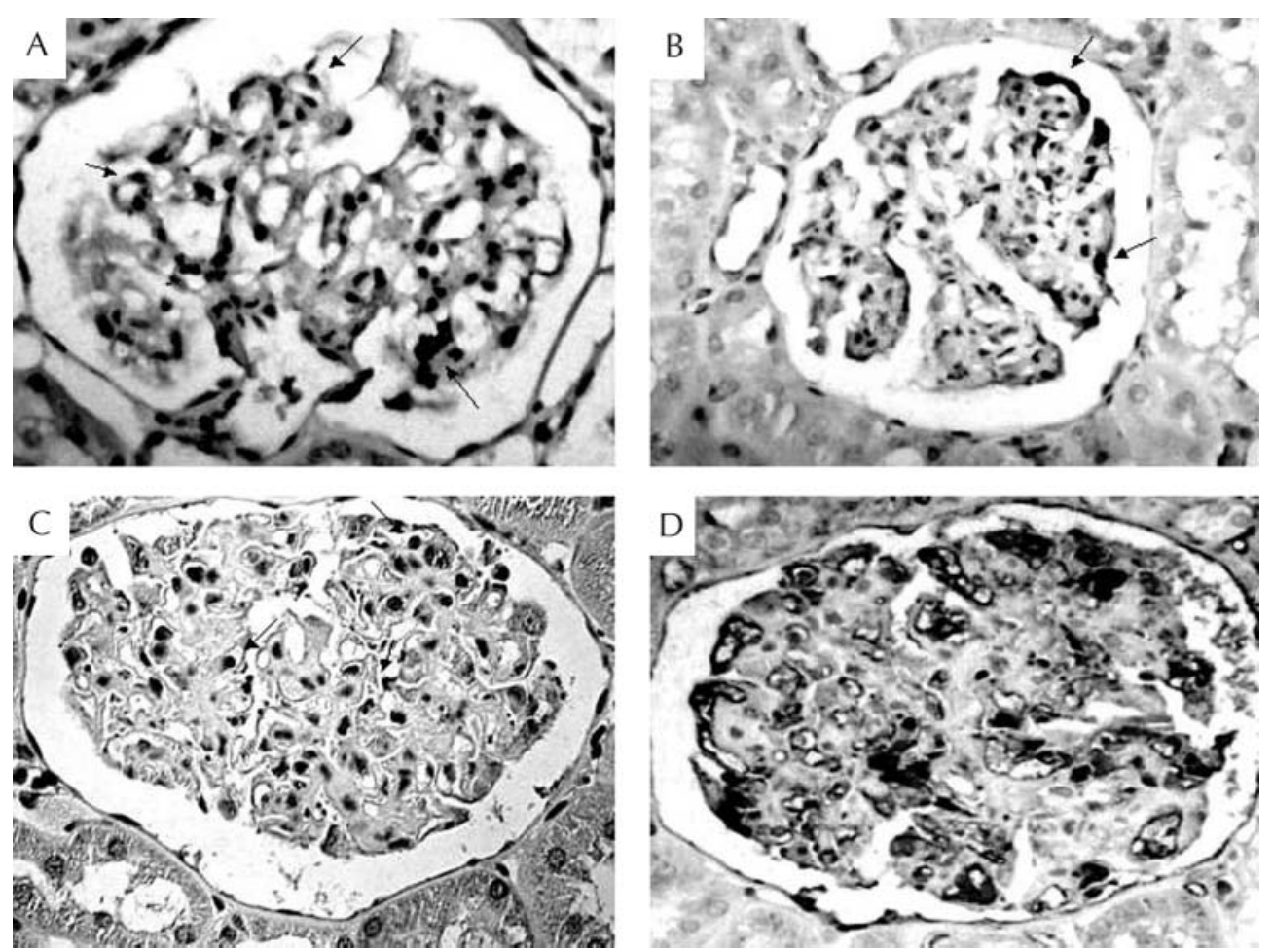

Figure 4 Immunohistochemistry of VEGF in experimental animals versus diabetes mellitus duration. (A) LETO rat at 55 weeks of age; (B) OLETF rat at 17 weeks of age; (C) OLETF rat at 25 weeks of age; (D) OLETF rat at 55 weeks of age. Positive staining for VEGF was detected in visceral epithelial cells (arrow). Glomerular staining for VEGF was markedly increased at 25 weeks of age and then increased with diabetes mellitus duration. $\times 400$.

In the present study, we serially observed changes in urinary albumin and urinary VEGF excretion, and glomerular VEGF mRNA expression and protein production. The glomerular VEGF gene transcript and urinary VEGF excretion increased in parallel and peaked at around 25 weeks of age, and then gradually decreased. In agreement with previous reports, VEGF proteins were found to be localized primarily in glomerular epithelial cells in both control and diabetic rats (Monacci et al. 1993, Simon et al. 1995). Although we did not demonstrate a direct causal role for VEGF in terms of the induction of albuminuria, the present data suggest a causative role for VEGF in the pathophysiology of early diabetic renal disease. Thus, it is tempting to speculate that increased intraglomerular VEGF synthesis may be important in the early stages of diabetic glomerular injury, and that this predates the appearance of overt structural damage.

The mechanisms of increased vascular permeability by VEGF may involve the stimulation of collagenase production (Unemori et al. 1992), the induction of endothelial fenestrae (Esser et al. 1998), the stimulation of nitric oxide production in endothelial cells (Papapetropoulos et al. 1997, Van der Zee et al. 1997), and an increase in glomerular filtration surface area by an augmentation of glomerular capillary endothelial cell growth (Nyengaard \& Rasch 1993). Antonetti et al. (1998) reported that vascular permeability in experimental diabetes is associated with reduced endothelial occludin, a tight-junction protein between endothelial cells. With regard to vascular permeability, Williams et al. (1996) showed that an acute infusion of VEGF into experimental animals markedly increased sciatic nerve and aortic albumin permeability.

In the present study, we show for the first time that urinary VEGF levels increase in accordance with intraglomerular VEGF mRNA expression and VEGF immunostaining, suggesting that urinary VEGF may reflect reliable intrarenal changes caused by these stimuli in the diabetic milieu. Furthermore, we found that urinary VEGF levels correlate strongly with 24-h albumin excretion.

In our experiment, UAE was higher in diabetic rats than in control rats throughout the study period. Consistent with previous reports, mesangial expansion was found to be preceded by the development of albuminuria (Fukuzawa et al. 1996, Tsuchida et al. 1999). Moreover, an increase in the glomerular mRNA expression of VEGF and urinary VEGF excretion was found to precede the occurrence of mesangial sclerosis. 

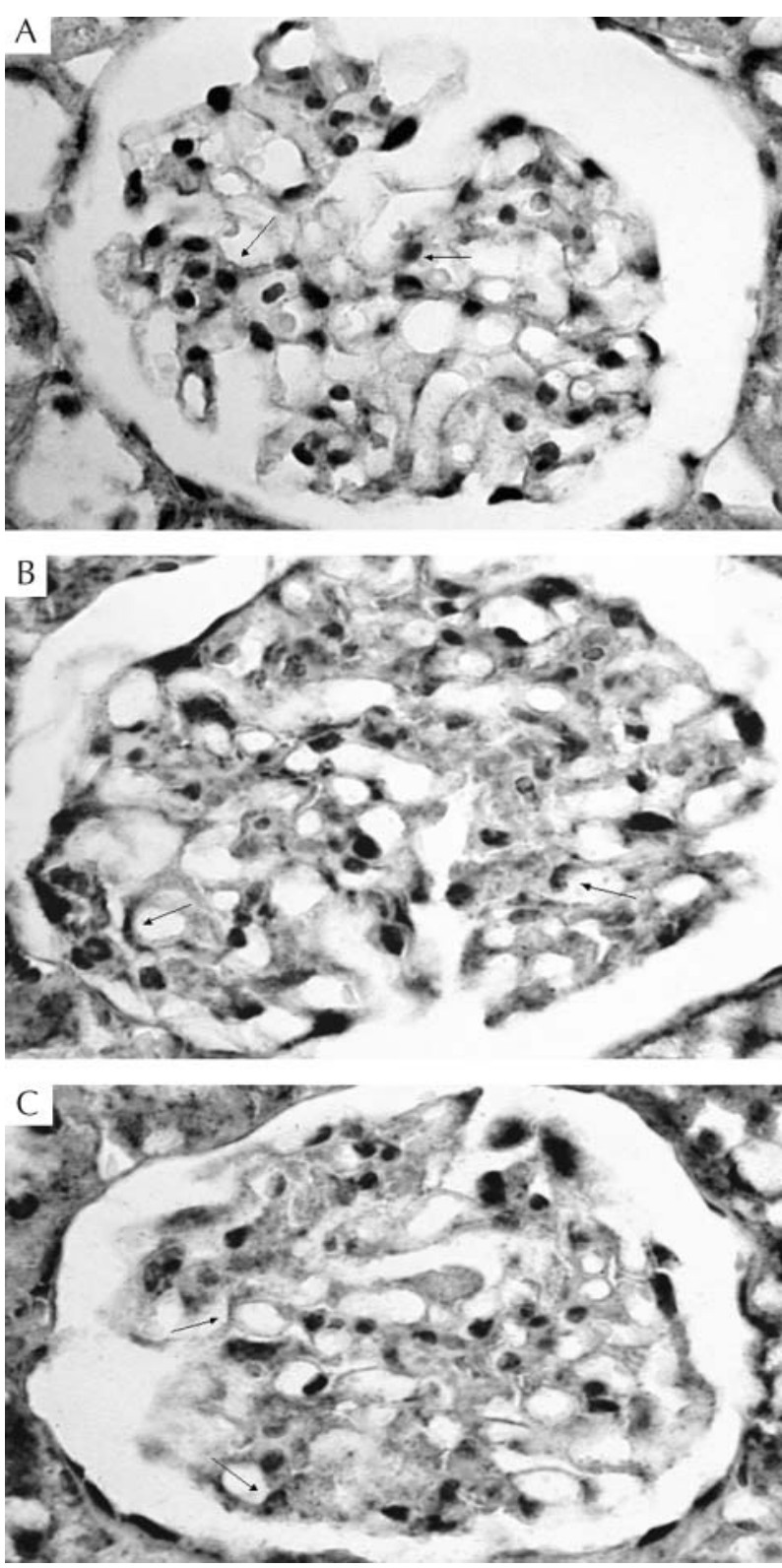

Figure 5 In situ hybridization of VEGF mRNA in the glomeruli of experimental animals versus diabetes mellitus duration. (A) LETO rat at 55 weeks of age; (B) OLETF rat at 17 weeks of age; (C) OLETF rat at 37 weeks of age. Hybridization was present in the glomerular visceral epithelial cells (arrows) of both LETO and OLETF rats. No specific hybridization was detected in tissues by VEGF sense probes. magnification: $\times 400$.

In this study, the glomerular immunostaining for VEGF was increased until 55 weeks of age. However, urinary VEGF excretion was elevated at the early period of nephropathy, and then fell to control levels. Decreased urinary VEGF excretions at the later stage of diabetic nephropathy may be due to the loss of podocytes, which are the major source of VEGF secretion in the glomeruli.

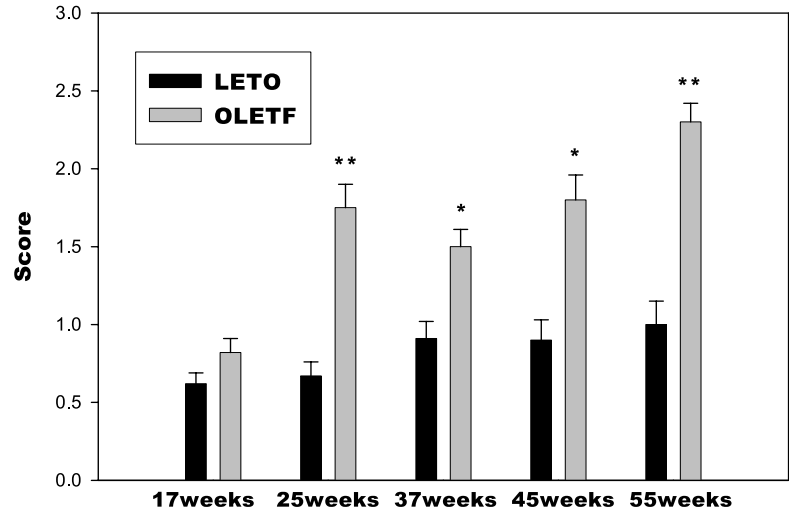

Figure 6 Glomerular immunohistochemical staining scores for VEGF in experimental animals versus diabetes mellitus duration. Glomerular immunostaining scores for VEGF were significantly elevated at 25 weeks of age and increased with diabetes mellitus duration. Data shown are means \pm S.D. ${ }^{*} P<0 \cdot 05$, ${ }^{*} P<0.01$ vs LETO.

However, cell-associated VEGF isoforms can be deposited in the extracellular matrix, which is increased during the course of diabetic nephropathy, and could be detected by immunohistochemical staining.

In this study, glomerular VEGF mRNA expression and urinary excretion were at a higher level in diabetic rats throughout the observation period. Various mechanisms could be responsible for this observed upregulation. Diabetes results in several pathobiologic changes, such as the activation of protein kinase C (Uchida et al. 1994, Williams et al. 1997) (generally recognized as a key mediator of the cellular response to hyperglycemia), advanced glycosylation end product (Yamagishi et al. 2002), the upregulation of cytokines and growth factors (including transforming growth factor (TGF)- $\beta$ (Pertovaara et al. 1994)) and of reactive oxygen species (Tilton et al. 1997), and stimulation of the renin-angiotensin system (Williams et al. 1995, Gruden et al. 1999, Pupilli et al. 1999). All of these changes are known to increase renal VEGF production. To summarize, many stimuli that act either independently or in combination may increase VEGF production in the diabetic kidney.

In the present study, however, marked upregulation of VEGF synthesis was observed during the early stage of diabetic nephropathy. This led to speculation that early diabetic glomerular injury might induce VEGF production by the kidney, especially by podocytes, and that this may lead to albuminuria. Therefore, VEGF may participate in the progression of the early stage of diabetic glomerular injury. The decreased VEGF synthesis in the later stage of diabetic nephropathy observed in this study may be due to the loss of podocytes, which are the main cellular source of VEGF synthesis in the glomeruli.

In conclusion, a significant increase in VEGF mRNA expression was observed during the early period of diabetic 


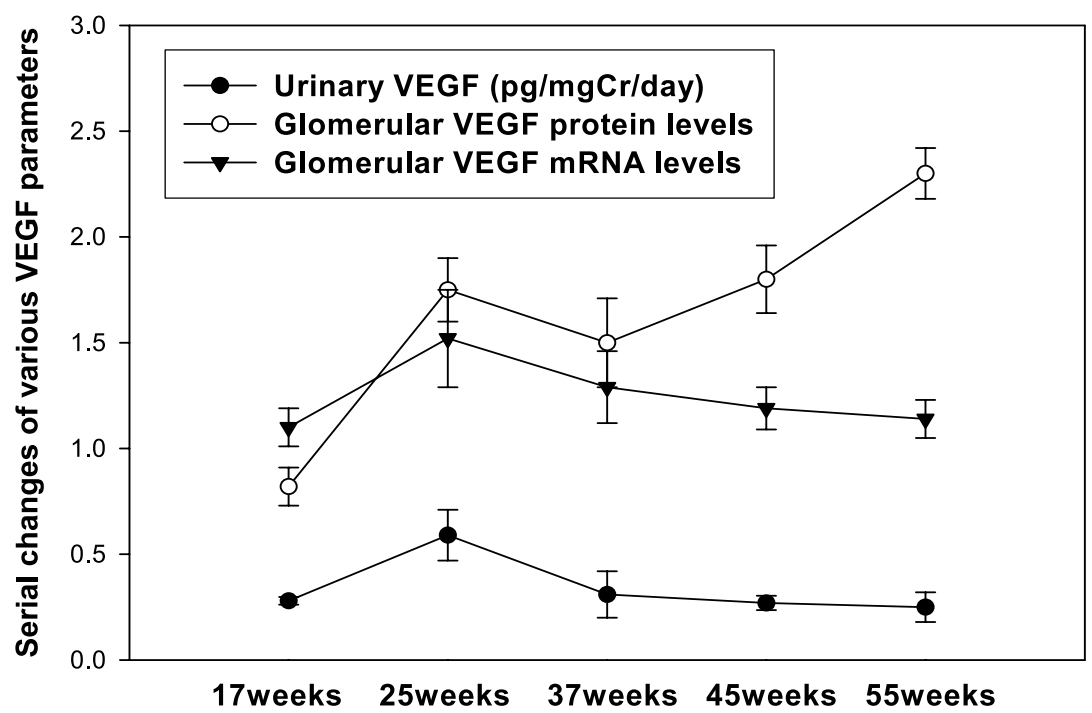

Figure 7 Serial changes in urinary VEGF excretion, glomerular VEGF mRNA expression and protein levels in OLETF rats versus diabetes mellitus duration. Glomerular VEGF mRNA and urinary VEGF levels increased in concert, peaked at 25 weeks of age and then gradually decreased.

nephropathy and glomerular VEGF gene transcription was associated with an increase in the urinary VEGF level. Moreover, urinary VEGF levels were found to be correlated strongly with 24-h albumin excretion. Our findings suggest that the overproduction of VEGF in the diabetic kidney participates in the pathogenesis of the early stage of diabetic nephropathy.

\section{Acknowledgements}

We thank the Tokushima Research Institute, Otsuka Pharmaceutical Co., Ltd, for providing the Otsuka-LongEvans-Tokushima-Fatty (OLETF) rats. This work was supported by a Korea Research Foundation Grant (KRF2002-003-E00076).

\section{References}

Abdel Aziz MY, Ben Gharbia O, El-Sayed Mohamed K, Muchaneta-Kubara EC \& El Nahas AM 1997 VEGF and diabetic microvascular complications. Nephrology, Dialysis, Transplantation 12 1538.

Antonetti DA, Barber AJ, Khin S, Lieth E, Tarbell JM \& Gardner TW 1998 Vascular permeability in experimental diabetes is associated with reduced endothelial occluding content: vascular endothelial growth factor decreases occluding in retinal endothelial cells. Penn State Retina Research Group. Diabetes 47 1953-1959.

Braun L, Kardon T, Reisz-Porszasz R, Banhegyi G \& Mandl J 2001 The regulation of the induction of vascular endothelial growth factor at the onset of diabetes in spontaneously diabetic rats. Life Sciences $692533-2542$

Cha DR, Kim NH, Yoon JW, Jo SK, Cho WY, Kim HK \& Won NH 2000 Role of vascular endothelial growth factor in diabetic nephropathy. Kidney International 58 (Suppl 77) S104-S112.
Clauss M, Gerlach M, Gerlach H, Brett J, Wang F, Familletti PC, Pan YC, Olander JV, Connolly DT \& Stern D 1990 Vascular permeability factor: a tumor-derived polypeptide that induces endothelial cells monocyte procoagulant activity, and promotes monocyte migration. Journal of Experimental Medicine $\mathbf{1 7 2}$ $1535-1545$.

Cooper ME, Vranes D, Youssef S, Stacker SA, Cox AJ, Rizkalla B, Casley DJ, Bach LA, Kelly DJ \& Gilbert RE 1999 Increased renal expression of vascular endothelial growth factor (VEGF) and its receptor VEGFR-2 in experimental diabetes. Diabetes $\mathbf{4 8}$ 2229-2239.

Cruz CI, Ziyadeh FN, Isono M, Kouahou M, Han DC, Kalluri R, Mundel P \& Chen S 2002 Effects of high glucose and TGF- $\beta 1$ on the expression of collagen IV and vascular endothelial growth factor in mouse podocytes. Kidney International 62 901-913.

De Vriese A, Tilton RG, Elger M, Stephan CC, Kriz W \& Lameire NH 2001 Antibody against vascular endothelial growth factor improves early renal dysfunction in experimental diabetes. Journal of American Society of Nephrology 12 993-1000.

Duh E \& Aiello LP 1999 Vascular endothelial growth factor and diabetes; the agonist versus antagonist paradox. Diabetes $\mathbf{4 8}$ 1899-1906.

Dvorak HF, Brown LF, Detmar M \& Dvorak AM 1995 Vascular permeability factor/vascular endothelial growth factor, microvascular hyperpermeability, and angiogenesis. American Journal of Pathology 146 1029-1039.

Esser S, Wolburg K, Wolburg H, Breier G, Kurzchalia T \& Risau W 1998 Vascular endothelial growth factor induces endothelial fenestrations in vitro. Journal of Cell Biology 140 947-959.

Ferrara N 1999 Role of vascular endothelial growth factor in regulation of angiogenesis. Kidney International 56 794-814.

Flyvbjerg A, Dagnaes-Hansen F \& De Vriese AS 2002 Amelioration of long-term renal changes in obese type 2 diabetes mice by a neutralizing vascular endothelial growth factor antibody. Diabetes $\mathbf{5 1}$ 3090-3094.

Fukuzawa Y, Watanabe Y, Inaguma D \& Hotta N 1996 Evaluation of glomerular lesion and abnormal urinary findings in OLETF rats resulting from a long-term diabetic state. Journal of Laboratory and Clinical Medicine 128 568-578. 
Gruden G, Thomas S, Burt D, Zhou W, Chusney G, Gnudi L \& Viberti G 1999 Interaction of angiotensin II and mechanical stretch on vascular endothelial growth factor production by human mesangial cells. Journal of American Society of Nephrology 10 730-737.

Horita Y, Miyazaki M, Koji T, Kobayashi N, Shibuya M, Razzaque MS, Cheng M, Ozono Y, Kohno S \& Taguchi T 1998 Expression of vascular endothelial growth factor and its receptors in rats with protein-overload nephrosis. Nephrology, Dialysis, Transplantation 13 2519-2528.

Hoshi S, Shu Y, Yoshida F, Inagaki T, Sonoda J, Watanabe T, Nomoto K \& Nagata M 2002 Podocyte injury promotes progressive nephropathy in Zucker diabetic fatty rats. Laboratory Investigation $\mathbf{8 2}$ 25-35.

Hovind P, Tarnow L, Oestergaard PB \& Parving HH 2000 Elevated vascular endothelial growth factor in type 1 diabetic patients with diabetic nephropathy. Kidney International 57 (Suppl 75) S56-S61.

Kawano K, Hirashima T, Mori S \& Natori T 1992 Spontaneous long-term hyperglycemic rat with diabetic complications; Otsuka Long-Evans Tokushima Fatty (OLETF) strain. Diabetes $\mathbf{4 1}$ 1422-1428.

Klanke B, Simon M, Röckl W, Weich HA, Stolte H \& Gröne HJ 1998 Effects of vascular endothelial growth factor (VEGF)/vascular permeability factor (VPF) on hemodynamics and permselectivity of the isolated perfused rat kidney. Nephrology, Dialysis, Transplantation 13 875-885.

Matsumoto K \& Kanmatsuse K 2001 Elevated vascular endothelial growth factor levels in the urine of patients with minimal-change nephritic syndrome. Clinical Nephrology 55 269-274.

Monacci WT, Merrill MJ \& Oldfield EH 1993 Expression of vascular permeability factor/vascular endothelial growth factor in normal renal tissues. American Journal of Physiology 264 C995-C1002.

Nyengaard JR \& Rasch RC 1993 The impact of experimental diabetes mellitus in rats on glomerular capillary number and sizes. Diabetologia 36 189-194.

Papapetropoulos A, Garcia-Cardena G, Madri JA \& Sessa WC 1997 Nitric oxide production contributes to the angiogenic properties of vascular endothelial growth factor in human endothelial cells. Journal of Clinical Investigation 100 3131-3139.

Pertovaara L, Kaipainen A, Mustonen T, Orpana A, Ferrara N, Saksela O \& Alitalo K 1994 Vascular endothelial growth factor is induced in response to transforming growth factor- $\beta$ in fibroblastic and epithelial cells. Journal of Biological Chemistry $2696271-6274$.

Pupilli C, Lasagni L, Romagnani P, Bellini F, Mannelli M, Misciglia N, Mavilia C, Vellei U, Villari D \& Serio M 1999 Angiotensin II stimulates the synthesis and secretion of vascular permeability factor/vascular endothelial growth factor in human mesangial cells. Journal of American Society of Nephrology 10 245-255.

Santilli F, Spagnoli A, Mohn A, Tumini S, Verrotti A \& Cipollone F 2001 Increased vascular endothelial growth factor serum concentrations may help to identify patients with onset of type 1 diabetes during childhood at risk for developing persistent microalbuminuria. Journal of Clinical Endocrinology and Metabolism 86 3871-3876.

Shulman K, Rosen S, Tognazzi K, Manseau EJ \& Brown LF 1996 Expression of vascular permeability factor (VPF/VEGF) is altered in many glomerular diseases. Journal of American Society of Nephrology 7 661-666.
Simon M, Gröne HJ, Jöhren O, Kullmer J, Plate H, Risau W \& Fuchs E 1995 Expression of vascular endothelial growth factor and its receptors in human renal ontogenesis and in adult kidney. American Journal of Physiology 268 F240-F250.

Tilton RG, Kawamura T, Chang KC, Ido Y, Bjercke RJ, Stephan CC, Brock TA \& Williamson JR 1997 Vascular dysfunction induced by elevated glucose levels in rats is mediated by vascular endothelial growth factor. Journal of Clinical Investigation $\mathbf{9 9}$ 2192-2202.

Tsuchida K, Makita Z, Yamagishi S, Atsumi T, Miyoshi H, Obara S, Ishida M, Ishikawa S, Yasumura K \& Koike T 1999 Suppression of transforming growth factor $\beta$ and vascular endothelial growth factor in diabetic nephropathy in rats by a novel advanced glycation end product inhibitor, OPB-9195. Diabetologia 42 579-588.

Uchida K, Uchida S, Nitta K, Yumura W, Marumo F \& Nihei H 1994 Glomerular endothelial cells in culture express and secrete vascular endothelial growth factor. American Journal of Physiology 266 F81-F88.

Unemori EN, Ferrara N, Bauer EA \& Amento EP 1992 Vascular endothelial growth factor induces interstitial collagenase expression in human endothelial cells. Journal of Cellular Physiology 153 557-562.

Van der Zee R, Murohara T, Luo Z, Zollman F, Passeri J \& Lekutat C 1997 Vascular endothelial growth factor/vascular permeability factor augment nitric oxide release from quiescent rabbit and human vascular endothelium. Circulation 95 1030-1037.

Wasada T, Kawahara R, Katsumori K, Naruse M \& Omori Y 1998 Plasma concentration of immunoreactive vascular endothelial growth factor and its relation to smoking. Metabolism 47 27-30.

Webb NJA, Watson CJ, Roberts ISD, Bottomley MJ, Jones CA, Lewis MA, Postlethwaite RJ \& Brenchley PEC 1999 Circulating vascular endothelial growth factor is not increased during relapses of steroid-sensitive nephritic syndrome. Kidney International $\mathbf{5 5}$ 1063-1071.

Williams B, Quinn Baker A, Gallacher B \& Lodwick D 1995 Angiotensin II increases vascular permeability factor gene expression by human vascular smooth muscle cells. Hypertension 25 913-917.

Williams B, Gallacher B, Pate H \& Orme C 1997 Glucose induced protein kinase $\mathrm{C}$ activation regulates vascular permeability factor mRNA expression and peptide production by human vascular smooth muscle cells in vitro. Diabetes 46 1497-1503.

Williamson JR, Chang KC, Stephan CC, Brock TA \& Tilton RG 1996 Links between neural and aortic vascular dysfunction introduced by elevated glucose levels and VEGF. Diabetes 45 (Suppl 2) $66 \mathrm{~A}$.

Yamagishi S, Inagaki Y, Okamoto T, Amano S, Koga K, Takeeuchi M \& Makita Z 2002 Advanced glycation end product-induced apoptosis and overexpression of vascular endothelial growth factor and monocyte chemoattractant protein-1 in human cultured mesangial cells. Journal of Biological Chemistry 277 20309-20315.

Received in final form 25 June 2004

Accepted 6 July 2004

Made available online as an

Accepted Preprint 19 July 2004 